\title{
Overcoming barriers of retinal care delivery during a pandemic - attitudes and drivers for the implementation of digital health: a global expert survey
}

\author{
Livia Faes $\mathbb{B}^{1},{ }^{1,2}$ Amir Rosenblatt, ${ }^{3}$ Roy Schwartz $\mathbb{B}^{1},{ }^{1}$ Sara Touhami $\left(\mathbb{0},{ }^{4}\right.$ \\ Camila V Ventura (10, ${ }^{5,6}$ Irini P Chatziralli (ㄷ, ${ }^{7}$ Jorge Ruiz-Medrano $\mathbb{C}^{8}{ }^{8}$ Denise Vogt, ${ }^{9}$ \\ Alfonso Savastano (1), ${ }^{10}$ Humberto Ruiz-Garcia, ${ }^{11}$ Dominika Pohlmann, ${ }^{12}$ \\ Anat Loewenstein, ${ }^{3}$ on behalf of the International Retinal Collaborative
}

- Supplemental material is published online only. To view please visit the journal online (http://dx.doi.org/10.1136/ bjophthalmol-2020-316882).

For numbered affiliations see end of article.

Correspondence to Anat Loewenstein, Division of Ophthalmology, Tel-Aviv Sourasky Medical Center, Sackler Faculty of Medicine, Tel-Aviv University, Weizmann St 6, Tel Aviv-Yafo, Israel; anat|@tlvmc.gov.il

Received 10 May 2020 Revised 11 July 2020 Accepted 4 September 2020

\section{ABSTRACT}

Background/Aims The SARS-CoV-2 pandemic has imposed barriers to retinal care delivery worldwide. In this context, retinal services are exploring novel ways to ensure access to healthcare.

Methods We conducted a worldwide survey among retinal specialists between March 31, 2020 and April 12, 2020. The expert survey was developed on the basis of focus group discussions involving retinal specialists and literature searches. It included 44 questions on alternative ways of care provision including digital health domains such as teleophthalmology, home monitoring or decentralised patient care.

Results 214 retinal experts participated in the survey, of which $120(56.1 \%)$ had more than 15 years of experience in ophthalmology. Most participants were clinicians $(n=158,73.9 \%)$ practising in Western Europe $(n=159$, $74 \%$ ). In the majority of institutions, teleophthalmology, home monitoring and decentralised patient care have not been implemented before the pandemic $(n=46,21.8 .1 \%$; $n=64,29.9 \% ; n=38,19.1 \%)$. During the pandemic, the use of teleophthalmology and home monitoring increased significantly $(n=105, p<0.001 ; n=90, p<0.001)$. In the subgroup of institutions reporting no teleophthalmology service before and implementing a service during the pandemic $(34 / 70,48.6 \%)$, reimbursement was the sole significant parameter (OR $9.62(95 \% \mathrm{Cl} 2.42$ to 38.16$)$; $\mathrm{p}<0.001)$.

Conclusion Digital health is taking the centre stage tackling unpreceded challenges of retinal care delivery during the SARS-CoV-2 pandemic and may sustainably change the way we practice ophthalmology.

\section{INTRODUCTION}

In ophthalmology, the term 'digital transformation' refers to the integration of digital services into eye care structures with the purpose of increasing efficiency of healthcare delivery. ${ }^{1}$ In retinal care, the unmet need has fostered innovative concepts and technology for care delivery prior to the SARSCoV-2 pandemic and in some cases even led to earlystage implementations. ${ }^{2-4}$ Nevertheless, while individual programmes may have been successful, largescale digital transformation has faced substantial barriers including regulatory and organisational hurdles or poor acceptance by clinicians and patients. ${ }^{5-7}$

The international attempt to reduce SARS-CoV-2 transmission by mandated 'social distancing' prompted a restriction of face-to-face consultations, contact time and physical proximity in routine ophthalmic assessments. ${ }^{8} 9$ Inevitably, ophthalmic institutions-impeded to deliver routine carerefuelled the discussion about alternative ways of service provision, and digital healthcare delivery has been moved to the forefront of medical practice. ${ }^{10}$ Remote patient management systems as used by teleophthalmology or home monitoring have been proposed for the safe access and delivery of retinal care. ${ }^{10}{ }^{11}$ Teleophthalmology has been adopted for risk stratification and triage or to substitute face-to-face examinations. ${ }^{12-14}$ In chronic retinal disease, home monitoring has been used for follow-up and reassurance of patients. ${ }^{10}$ Finally, patient care has been decentralised to non-medical settings during the pandemic to keep patients away from crowded hospitals and clinics. ${ }^{15}$

By disrupting long-standing practice, this pandemic offers the unique opportunity to investigate expedited digital health transformation in challenged healthcare systems.

In this study, we therefore conducted a worldwide expert survey, involving leaders in the field of retinal diseases, to (i) investigate their attitudes towards digital health, in particular remote management systems; (ii) assess the extent to which transformations occur due to the current pandemic and (iii) explore drivers and barriers of digital health transformation.

\section{MATERIALS AND METHODS}

\section{Survey development}

This expert survey was developed on the basis of a literature review and discussions held by a focus group of 10 retina specialists. The group discussions were held remotely. Participants reviewed pertinent issues regarding the management of retinal diseases, modern ways of care delivery and their barriers, particularly in regard to digital health services. Briefly, the group reflection indicated that retinal care delivery involving digital health fell into three 
categories: teleophthalmology, home monitoring and decentralised patient care. In addition, understanding potential barriers and drivers in the context of the respective healthcare system (ie, in view of reimbursement and infrastructure) was considered important.

The group then reviewed the scientific evidence for these three domains, aiming at achieving in-depth knowledge on a more granular level about teleophthalmology, home monitoring and decentralised care. ${ }^{16-19}$ The review revealed associated topics of teleophthalmology such as automated, remote or electronic triage, smart-history taking, virtual consultations or clinics, electronic referrals, multimodal imaging approaches as a substitute of face-to-face investigations, and automated image analysis or decision-making (ie, via artificial intelligence algorithms). ${ }^{16-18} \quad 20-22$ The initial survey draft was reviewed by 10 retinal specialists and was modified after being tested by 20 additional retinal specialists who volunteered to participate. The final expert survey was organised into three sections (teleophthalmology, home monitoring and other types of decentralised patient care) with a definition of the terms and illustrative examples preceding the respective subsection to ensure a common understanding of participating experts. In total, the survey comprised 44 questions including basic information on the demographics of the experts (6 questions), the institutions in which they practise ophthalmology and their infrastructure (5 questions), attitudes towards digital health (11 questions) and the impact on the implementation of digital health solutions during the pandemic (22 questions). Question types involved single-choice (21), multiple-choice 'please select all that apply' (12), Likert scales (6) and fulltext answers (5). The survey was conducted in English exclusively (see online supplemental file 1 ).

\section{Independent and dependent measures and variables}

Independent measures involved questions on participants' demographics (ie, sex, age, country of practice, years of experience in ophthalmology, expertise and current job positions) and their respective institutions (ie, setting, health records system, state of the infrastructure, state of interdisciplinary work and reimbursement structure).

Dependent measures involved questions on (i) participants' attitudes towards digital health before and during the pandemic (ie, its usefulness, implications for future applications and barriers) and (ii) the level of implementation of digital health services in their institutions before and during the pandemic (ie, how frequent and for what purpose was/is teleophthalmology, home monitoring and other types of decentralised patient care used?). In addition, participants were asked about current practice patterns in regard to the management of retinal diseases in their institutions and about their opinion on which patients are at particular risk for permanent vision loss in case of delayed management during the pandemic.

\section{Participant selection}

From the Masterfile of the 11th Annual Congress on Controversies in Ophthalmology (Europe COPHY 2020) and the Macula Society membership directory, we aimed to identify all retinal experts defined as consultant or fellowship level knowledge on retinal disease. Additionally, retinal specialists from Asia, Africa, North America, South America, Europe and Australia were contacted by the authors of this study via their professional network. Of about 600 retinal specialists contacted in total, 214 completed the questionnaire. To calculate the overall response rate, we divided the number of completed questionnaires by the number of contacted specialists. This yielded a rough estimate of a response rate of $36 \%$.

\section{Survey administration}

Between March 31, 2020 and April 12, 2020, experts received a cover letter and link to access the survey on Google forms via email. The anonymity of the respondents was guaranteed. Nonrespondents were not contacted repeatedly. We did not offer reimbursement for participation.

\section{Statistical analysis}

Continuous variables were described using means and standard deviation (SD) and dichotomous variables with percentages. To assess the association between specialists' demographics, attitudes and characteristics of their respective institutions and reimbursement structures (independent variables) on the novel adoption of the three digital health innovations (teleophthalmology, home monitoring and decentralised patient care: dependent variables), three separate logistic regression models were fitted. Parameters with a statistically significant association with the outcome were considered. A p value of less than 5\% was considered statistically significant. To assess before-after effects, we compared changes in the percentages of participants stating no activity within one of the three outcome domains (teleophthalmology, home monitoring and decentralised care) and tested changes statistically using the McNemar test. Analyses were performed using the Stata 16.1 statistics software package (StataCorp. 2019, Stata Statistical Software: Release 16. StataCorp LLC, College Station, Texas, USA).

\section{RESULTS}

\section{Participants' demographics}

Of the 214 participating experts, 97 (45.3\%) were women and 1 person $(0.5 \%)$ preferred not to disclose his or her gender. Most participants were older than 40 years $(n=140,65.4 \%)$. Most experts practised in Western Europe $(n=152,70.7 \%)$, followed by South America $(n=15,7 \%)$ and North Africa $(n=10,4.7 \%)$ while Australian experts were least represented $(n=2,0.9 \%)$. Most of the participants were clinicians $(n=158,73.9 \%)$ or clinical academics $(n=44,20.8 \%)$ with over 15 years of experience in ophthalmology $(n=120,56.1 \%)$. All participants had expertise in medical retina, and 123 (57.2\%) reported additional expertise in vitreoretinal diseases. Neither age nor the level of experience were associated with attitudes towards digital health or the extent to which it was implemented in institutions (table 1).

\section{Setting and infrastructure}

One hundred and thirty-eight experts $(64.6 \%)$ were affiliated to a tertiary care institution and $102(47.7 \%)$ were affiliated to a secondary care institution. Most experts were able to access patient records electronically $(n=151,70.6 \%)$. On a 5-point Likert scale, the information technology infrastructure was predominantly described as average (' 3 ': $n=70,32.7 \%$ ) or good (' 4 ': $n=74$, $34.6 \%$ ), as was the degree of interdisciplinary work among eye care professionals ('average' $n=60,28 \%$; 'good' $n=88,41.1 \%$ ). Reimbursement of teleophthalmology services was reported by 92 participants (43\%), while home monitoring and other types of decentralised patient care were reimbursed in 12 (5.6\%) and 22 (10.9\%) of the institution experts reported on, respectively (table 2).

\section{Patients with retinal disease at particular risk for permanent} vision loss during the pandemic

Participating retinal experts identified wet age-related macular degeneration $(\mathrm{n}=118,84.6 \%)$, retinal detachments 
Table 1 Demographic information of experts participating in the survey

\begin{tabular}{|c|c|c|c|c|c|c|}
\hline \multicolumn{7}{|l|}{ Total $n=214$} \\
\hline \multicolumn{7}{|l|}{ Gender } \\
\hline & $\begin{array}{l}\text { Men } \\
116(54.2 \%)\end{array}$ & $\begin{array}{l}\text { Women } \\
97(45.3 \%)\end{array}$ & $\begin{array}{l}\text { Prefer not to say } \\
1(0.5 \%)\end{array}$ & & & \\
\hline \multicolumn{7}{|l|}{ Age in years } \\
\hline & $\begin{array}{l}18-30 \text { years } \\
10(4.6 \%)\end{array}$ & $\begin{array}{l}31-40 \text { years } \\
64(29.9 \%)\end{array}$ & $\begin{array}{l}41-50 \text { years } \\
45(21.1 \%)\end{array}$ & $\begin{array}{l}51-60 \text { years } \\
43(20.1 \%)\end{array}$ & $\begin{array}{l}60-65 \text { years } \\
34(15.9 \%)\end{array}$ & $\begin{array}{l}>65 \text { years } \\
18(8.4 \%)\end{array}$ \\
\hline \multicolumn{7}{|l|}{ Country of practice } \\
\hline & $\begin{array}{l}\text { Western Europe } \\
152(70.7 \%)\end{array}$ & $\begin{array}{l}\text { Eastern Europe } \\
4(1.9 \%)\end{array}$ & $\begin{array}{l}\text { United Kingdom } \\
7(3.3 \%)\end{array}$ & $\begin{array}{l}\text { United States } \\
8(3.7 \%)\end{array}$ & $\begin{array}{l}\text { Australia } \\
2(0.9 \%)\end{array}$ & $\begin{array}{l}\text { North Africa } \\
10(4.7 \%)\end{array}$ \\
\hline & $\begin{array}{l}\text { South East Asia } \\
8(3.7 \%)\end{array}$ & $\begin{array}{l}\text { Middle East } \\
5(2.3 \%)\end{array}$ & $\begin{array}{l}\text { South America } \\
15(7 \%)\end{array}$ & $\begin{array}{l}\text { Other } \\
4(1.8 \%)\end{array}$ & & \\
\hline Job title* & $\begin{array}{l}\text { Clinician } \\
158(73.9 \%)\end{array}$ & $\begin{array}{l}\text { Clinical academic } \\
44(20.8 \%)\end{array}$ & $\begin{array}{l}\text { Purely academic } \\
9(4.2 \%)\end{array}$ & $\begin{array}{l}\text { Consultant } \\
36(16.8 \%)\end{array}$ & $\begin{array}{l}\text { Head of } \\
\text { a department } 24 \\
(11.2 \%)\end{array}$ & \\
\hline $\begin{array}{l}\text { Ophthalmology } \\
\text { experience in years }\end{array}$ & $\begin{array}{l}<5 \text { years } \\
17(7.9 \%)\end{array}$ & $\begin{array}{l}5-10 \text { years } \\
43(20.1 \%)\end{array}$ & $\begin{array}{l}11-15 \text { years } \\
34(15.9 \%)\end{array}$ & $\begin{array}{l}>15 \text { years } \\
120(56.1 \%)\end{array}$ & & \\
\hline Expertise* & $\begin{array}{l}\text { Medical retina } \\
215(100 \%)\end{array}$ & $\begin{array}{l}\text { Vitreous-retinal disease } \\
123(57.2 \%)\end{array}$ & $\begin{array}{l}\text { Uveitis } \\
85(39.5 \%)\end{array}$ & $\begin{array}{l}\text { Paediatric retinal diseases } \\
34(15.8 \%)\end{array}$ & $\begin{array}{l}\text { Retinal oncology } \\
20(9.3 \%)\end{array}$ & \\
\hline
\end{tabular}

*Participants chose all answers that applied. Proportions do not add up to 100 percent.

\begin{tabular}{|c|c|c|c|c|c|}
\hline \multicolumn{6}{|l|}{ Total $n=214$} \\
\hline Institution* & $\begin{array}{l}\text { Tertiary centre } \\
50(23.4 \%)\end{array}$ & $\begin{array}{l}\text { Tertiary centre within a hospital } \\
88(41.2 \%)\end{array}$ & $\begin{array}{l}\text { Secondary care } \\
102(47.7 \%)\end{array}$ & $\begin{array}{l}\text { Academia } \\
29(13.6 \%)\end{array}$ & \\
\hline Healthcare record system & $\begin{array}{l}\text { Electronic } \\
151(70.6 \%)\end{array}$ & $\begin{array}{l}\text { Paper-based } \\
24(11.2 \%)\end{array}$ & $\begin{array}{l}\text { Combined } \\
39(18.2 \%)\end{array}$ & & \\
\hline State of the IT infrastructure & $\begin{array}{l}\text { Very poor } \\
8(3.7 \%)\end{array}$ & $\begin{array}{l}\text { Poor } \\
19(8.9 \%)\end{array}$ & $\begin{array}{l}\text { Average } \\
70(32.7 \%)\end{array}$ & $\begin{array}{l}\text { Good } \\
74(34.6 \%)\end{array}$ & $\begin{array}{l}\text { Excellent } \\
43(20.1 \%)\end{array}$ \\
\hline Extent of interdisciplinary work & $\begin{array}{l}\text { Very poor } \\
12(5.6 \%)\end{array}$ & $\begin{array}{l}\text { Poor } \\
19(8.9 \%)\end{array}$ & $\begin{array}{l}\text { Average } \\
60(28 \%)\end{array}$ & $\begin{array}{l}\text { Good } \\
88(41.1 \%)\end{array}$ & $\begin{array}{l}\text { Excellent } \\
35(16.4 \%)\end{array}$ \\
\hline \multicolumn{6}{|l|}{ Reimbursement of digital health } \\
\hline Teleophthalmology & $\begin{array}{l}\text { Yes } \\
92(43 \%)\end{array}$ & $\begin{array}{l}\text { No } \\
80(37.4 \%)\end{array}$ & $\begin{array}{l}\text { Don't know } \\
42(19.6 \%)\end{array}$ & & \\
\hline Home monitoring & $\begin{array}{l}\text { Yes } \\
12(5.6 \%)\end{array}$ & $\begin{array}{l}\text { No } \\
159(74.3 \%)\end{array}$ & $\begin{array}{l}\text { Don't know } \\
43(20.1 \%)\end{array}$ & & \\
\hline Other types of decentralised patient care & $\begin{array}{l}\text { Yes } \\
22(10.3 \%)\end{array}$ & $\begin{array}{l}\text { No } \\
129(60.3 \%)\end{array}$ & $\begin{array}{l}\text { Don't know } \\
63(29.3 \%)\end{array}$ & & \\
\hline
\end{tabular}

*Participants chose all answers that applied. Proportions do not add up to 100 percent.

$(\mathrm{n}=189,88.3 \%)$, proliferative diabetic retinopathy $(\mathrm{n}=169$, $79 \%)$, uncontrolled (posterior) uveitis $(n=157,73.4 \%)$, retinal vein occlusions with neovascularisations $(n=156,72.9 \%)$, myopic choroidal neovascularisation $(n=147,68.7 \%)$ and retinopathy of prematurity $(n=114,53.3 \%)$ as retinal diseases that may render patients particularly vulnerable to permanent vision loss during the pandemic.

\section{Attitudes towards and opinions about digital health}

Opinions on barriers before the pandemic

One hundred and fifty-three participants (71.5\%) described the level of the provided infrastructure as a potential barrier for the implementation of digital health. Regarding factors that may challenge the adoption of digital health, 118 participants (55.1\%) stated reimbursement, 114 (53.3\%) stated patients' acceptance and $92(43 \%)$ stated doctors' acceptance. Two participants $(1 \%)$ highlighted security concerns (quality of imaging and examination). Four (1.9\%) experts reported no barriers to the implementation of digital health, and 14 (6.5\%) were undecided.

Attitudes towards usefulness before the pandemic

Teleophthalmology was considered 'not useful at all' $(n=52$, $24.3 \%)$ or 'not useful' $(n=68,31.8 \%)$ by the majority of participants before the pandemic. Home monitoring was considered useful by 125 (58.4\%) participants and 27 (12.6\%) were undecided. Moreover, the majority of experts described that they would feel 'not at all comfortable' ( $n=66,30.8 \%)$ or 'uncomfortable' $(\mathrm{n}=59,27.6 \%)$ to deliver decentralised patient care in nonmedical settings.

Attitudes towards applications of teleophthalmology during the pandemic

If all participating experts were to use teleophthalmology, they would use it for the purposes of triaging $(n=161,75.2 \%)$, counselling $(n=161,75.2 \%)$, follow-up $(n=152,71.0 \%)$ and therapy instruction $(\mathrm{n}=150,70.1 \%)$. 
Opinions on the robustness of newly implemented digital healthcare solutions

While exactly half of the experts were convinced that the experiences they were making with teleophthalmology during the pandemic would sustainably change the way they will deliver retinal care in the future $(n=107,50.0 \%$ for 'yes', vs $n=46,21.5 \%$ for 'no' and $n=58,27.1 \%$ for 'don't know'), this was the case for only about one-third in regard to home monitoring $(n=70$, $32.9 \%$ for 'yes', $n=56,26.3 \%$ for 'no' and $n=84,39.4 \%$ for 'don't know') and other types of decentralised patient care ( $n=63,29.6 \%$ for 'yes', $n=79,37.1 \%$ for 'no' and $n=69$, $32.4 \%$ for 'don't know').

\section{Impact of the pandemic on the implementation of digital health}

Teleophthalmology

In the majority of institutions, teleophthalmology was not used before the pandemic. More particularly, smart-history taking was used by 41 (19.2\%), automated imaging analysis or decisionmaking by $21(9.8 \%)$, triage by $60(28 \%)$, virtual consultations or clinics by $25(16.4 \%)$ respectively, 33 (15.4\%), electronic referrals by $57(26.6 \%)$ and the substitution of slit-lamp examinations by $54(25.2 \%)$.

The use of teleophthalmology was significantly increased by the pandemic ( $n=46$ vs $n=105, p<0.001$, see figure 1$)$.

\section{Home monitoring}

Most institutions performed some kind of home monitoring before the pandemic $(n=168,79.5 \%)$. Most used paper-based $(n=150,70.1 \%)$, smartphone-based $(n=40,18.7 \%)$, and few hardware-based $(n=16,7.5 \%)$ home monitoring. Hyperacuity, metamorphopsia and scotoma were the visual qualities that were most frequently monitored $(n=115,53.7 \%)$, followed by visual acuity $(n=84,39.3 \%)$ and contrast sensitivity $(n=16,7.5 \%)$. Only a minority used home monitoring of retinal anatomy (optical coherence tomography, $\mathrm{n}=17$ and fundus photography $\mathrm{n}=17,7.9 \%)$. During the pandemic, $42.1 \%(\mathrm{n}=90)$ of the investigated institutions increased efforts to home-monitor. In $2.5 \%$ $(n=5)$ of cases, the extent of home monitoring was decreased. Overall, the use of home monitoring was significantly increased by the pandemic ( $n=64$ vs $n=90, p<0.001$, see figure 1 ).

Age-related macular degeneration $(n=146,68.2 \%)$, diabetic macular oedema $(n=74,34.6 \%)$ and cystoid macular oedema $(n=69,32.2 \%)$ were the most commonly monitored diseases before the pandemic.
Other types of decentralised care

In regard to other types of decentralised care, $14.6 \%$ were providing retinal care in non-medical settings (screening $\mathrm{n}=31$, $14.6 \%$; intravitreal injections $n=11,5.1 \%$ ) before the pandemic. Screening efforts were slightly reduced during the pandemic $(\mathrm{n}=25,11.7 \%)$ while decentralised intravitreal injections increased $(n=15,7.0 \%)$. Overall, decentralised care has not been significantly changed by the pandemic $(\mathrm{N}=199, \mathrm{n}=38$ vs $\mathrm{N}=198, \mathrm{n}=37, \mathrm{p}=1.000$ ) (see figure 1 ).

\section{Drivers for the implementation of digital health approaches}

In the subgroup of institutions reporting no teleophthalmology service before the pandemic and adopting it during the pandemic (34/70, 48.6\%), reimbursement was the sole significant parameter (Odds ratio (OR) 9.62 (95\% confidence interval (CI) 2.42 to 38.16$) ; \mathrm{p}>0.001)$. The same analyses performed for home monitoring or decentralised care revealed no significant association with other possible barriers.

\section{DISCUSSION \\ Main findings}

This study found a significant increase in the implementation of teleophthalmology and home monitoring services during the SARS-CoV-2 pandemic. Of note, other types of decentralised patient care initiatives, such as intravitreal injections in nonmedical settings, were infrequently adopted. The main driver for the implementation of teleophthalmology services in institutions that did not provide such service before the pandemic was reimbursement. The sceptical attitudes towards digital health found within an international group of retinal experts prior to the pandemic, however, stand in contrast to previously observed results in a general clinicians' population. ${ }^{23} 24$

\section{Results in the light of the existing literature}

This is the first study to investigate the impact of a global health crisis as an external disruptive force on digital health transformation in retinal care delivery. Indisputably, the SARS-CoV-2 pandemic has accelerated the transformation in a unique manner beyond previously described implementation strategies. In the United Kingdom, policymakers have even expressed enforcement discretion in regard to remote communication systems to empower healthcare providers. ${ }^{25} 26$

Within the three evaluated areas, retinal specialists showed the highest short-term acceptance towards teleophthalmology, followed by home monitoring. However, attitudes towards
Teleophthalmology

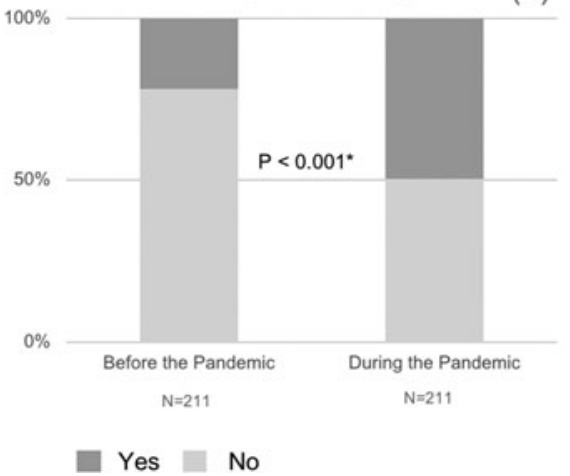

Home Monitoring

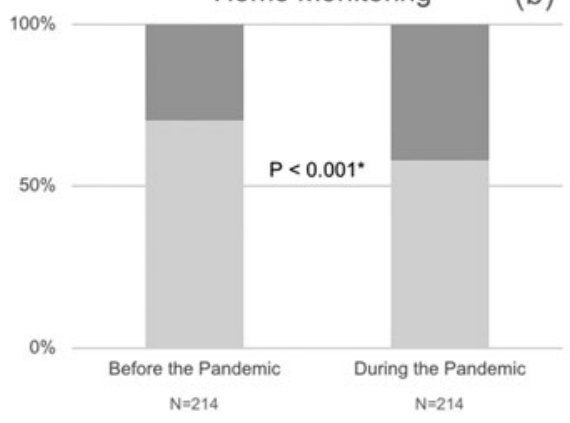

(b)

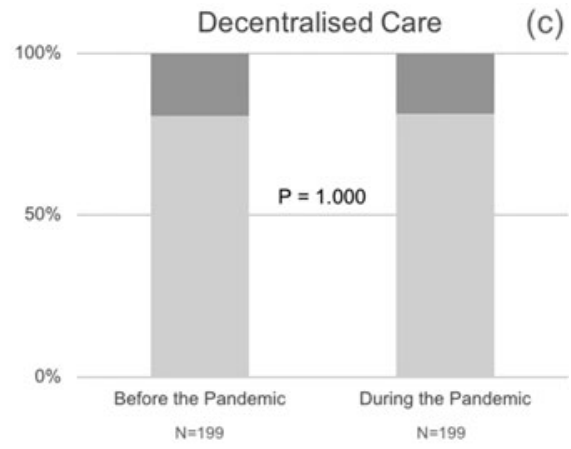

Figure 1 Comparison of the levels of implementation of teleophthalmology (A), home monitoring (B) and other types of decentralised care (C) before and during the pandemic. 
decentralizsed care initiatives remained at a low level and did not change significantly due to the pandemic. We speculate that the availability of teleophthalmology and home monitoring technology, as well as initial experience with these technologies prior to the pandemic, may have allowed for short-term introduction, while decentralised care may have encountered regulatory and procedural obstacles that are more time-consuming and complex to overcome. Regardless, the availability of a robust evidence base for digital health is necessary to build sufficient trust within the community to facilitate the implementation of digital health. Li et al's study, which compared the quality of routine care with a teleophthalmology service, showed no differences in the quality of care in terms of visual acuity in patients with age-related macular degeneration. ${ }^{27}$ For some time now, a collaborative project of the Big Picture Medical Platform with the Moorfields Eye Hospital (National Health Service Foundation Trust, London, United Kingdom) has been in progress. In preliminary analyses, the project showed significant efficiency gains in the organisation of a virtual medical retina clinic, in which mainly patients with diabetic retinopathy were treated. ${ }^{17}$ In the field of home monitoring, the external validity of the Amsler Grid-although popular in clinic-has been questioned. ${ }^{21} 28$ At the moment, preliminary evidence is available for two smartphone-based tests approved by the United States Food and Drug Administration, the mVT (Genentec) and Alleye (Oculocare medical). ${ }^{29} 30$ Decentralised care of age-related macular degeneration by means of intravitreal injections at the patient's home may prevent severe deterioration of vision in patients with little access to healthcare. In many countries, however, this form of care is still prohibited for regulatory reasons. It is therefore not surprising that activity in this area was hardly affected by the SARS-CoV-2 pandemic in our survey.

\section{Limitations}

The limitations of this study included the lack of validation of the survey prior to its application, which was reflected by the occurrence of incoherent answering patterns. Second, the selection process of experts was done in a non-random manner and is therefore likely to be non-representative of the diversity of the retinal expert community worldwide. Despite this limitation, it is a frequently conducted sampling method used in social science. ${ }^{31}$ The exclusive use of a Google product as a survey tool and the language restriction may have additionally limited representativeness. Another limitation to be considered is that we relied on participants' reports about practice patterns of their respective institutions and asked for their attitudes in retrospect (memory bias). However, the survey questionnaire format is an accepted approach for gathering knowledge on expert opinions, attitudes and practice patterns. ${ }^{32}$ Moreover, some of the questions bore high face validity and therefore suggestive character. Lastly, we were not able to objectively quantify the degree to which retinal care delivery has been impeded to contextualise participants' responses. ${ }^{33}$

\section{Implications for research}

Further studies may investigate attitudes of upcoming generations of retinal specialists towards digital health. Moreover, since this survey predominantly represents a European perspective on digital health, other geographic areas may be highlighted. With regard to a long-term perspective, robustness of newly implemented service extensions during the SARS-CoV-2 pandemic may be investigated.

\section{Implications for practice}

In Great Britain, nearly eighty percent of the consultations in ophthalmology have been cancelled during the SARS-CoV-2 pandemic. ${ }^{34}$ This disruption of retinal care delivery has expanded on the previous unmet need in eye care. Poorly prepared care structures necessitated hasty implementations of remote management systems, which offers now the opportunity to transform them into long-term solutions. A vital driver for this transformation, as identified by this expert survey, may be the reimbursement structure acknowledging the complementary role of digital care. Moreover, transferring care closely to the patient will require additional expertise coming from other areas than medicine. The development, maintenance and evolution of telemedical services require dedicated information specialists and engineers with sufficient insight into the clinical problem. Furthermore, particularly when implementing automated systems using artificial intelligence applications, staff with sufficient insight into the development and local adaptation of these algorithms should be available.

\section{CONCLUSION}

Digital health is taking the centre stage tackling the unpreceded challenges of retinal care delivery during a pandemic and may sustainably change the way we practice ophthalmology. Shortterm implementations may be transformed into permanent solutions if policymakers acknowledge their complementary role for care delivery.

\section{Author affiliations}

${ }^{1}$ Moorfields Eye Hospital NHS Foundation Trust, London, United Kingdom

${ }^{2}$ Eye Clinic of the Cantonal Hospital of Lucerne, Lucerne, Switzerland

${ }^{3}$ Division of Ophthalmology, Tel-Aviv Sourasky Medical Center, Tel-Aviv, Israel, Sackler Faculty of Medicine, Tel-Aviv University, Tel Aviv, Israel

${ }^{4}$ Department of Ophthalmology, Pitié Salpètriére University Hospital, Sorbonne Université, Paris, France

${ }^{5}$ Department of Ophthalmology, Altino Ventura Foundation, Recife, Brazil

${ }^{6}$ Department of Ophthalmology, HOPE Eye Hospital, Recife, Brazil

${ }^{7}$ 2nd Department of Ophthalmology, National and Kapodistrian University of Athens, Athens, Greece

${ }^{8}$ Department of Ophthalmology, Puerta de Hierro-Majadahonda University Hospital, Madrid, Spain

${ }^{9}$ Department of Ophthalmology, Ludwig-Maximilians-University Munich, Germany ${ }^{10}$ Department of Ophthalmology, Fondazione Policlinico Universitario A. Gemelli IRCCS, Rome, Italy

${ }^{11}$ Clinica Oftalmológica Santa Lucía, Guadalajara, Mexico

${ }^{12}$ Charité - Universitätsmedizin Berlin, corporate member of Freie Universität Berlin, Humboldt-Universität zu Berlin, and Berlin Institute of Health, Berlin, Germany

Twitter Roy Schwartz @royschwartz.

Contributors All authors contributed to the conception and design of the study and the administration of the survey. LF conducted data analyses. All authors contributed to the interpretation of the data and the writing of the manuscript. All authors reviewed the manuscript and contributed to its revisions.

Funding The authors have not declared a specific grant for this research from any funding agency in the public, commercial or not-for-profit sectors.

Competing interests None declared.

Provenance and peer review Not commissioned; externally peer reviewed.

Data availability statement Data are available upon reasonable request.

Supplemental material This content has been supplied by the author(s). It has not been vetted by BMJ Publishing Group Limited (BMJ) and may not have been peerreviewed. Any opinions or recommendations discussed are solely those of the author(s) and are not endorsed by BMJ. BMJ disclaims all liability and responsibility arising from any reliance placed on the content. Where the content includes any translated material, BMJ does not warrant the accuracy and reliability of the translations (including but not limited to local regulations, clinical guidelines, terminology, drug names and drug dosages), and is not responsible for any error and/ or omissions arising from translation and adaptation or otherwise.

This article is made freely available for use in accordance with BMJ's website terms and conditions for the duration of the COVID-19 pandemic or until otherwise determined by BMJ. You may use, download and print the article for any lawful, non- 
commercial purpose (including text and data mining) provided that all copyright notices and trade marks are retained.

\section{ORCID iDs}

Livia Faes http://orcid.org/0000-0002-4159-3960

Roy Schwartz http://orcid.org/0000-0003-3487-5713

Sara Touhami http://orcid.org/0000-0001-8346-3067

Camila V Ventura http://orcid.org/0000-0002-2927-4684

Irini P Chatziralli http://orcid.org/0000-0001-8523-1024

Jorge Ruiz-Medrano http://orcid.org/0000-0002-1105-9265

Alfonso Savastano http://orcid.org/0000-0003-1575-6567

\section{REFERENCES}

1 Meskó B, Drobni Z, Bényei É, et al. Digital health is a cultural transformation of traditional healthcare. Mhealth 2017:3:38.

2 Morse AR. Telemedicine in ophthalmology: promise and pitfalls. Ophthalmology 2014;121:809-11.

3 Number of ophthalmologists Europe 2017 | statista. Statista. Available https://www. statista.com/statistics/711061/number-of-ophthalmologists-in-european-union-eu/ (accessed 30 Mar 2020)

4 Resnikoff S, Lansingh VC, Washburn L, et al. Estimated number of ophthalmologists worldwide (International Council of Ophthalmology update): will we meet the needs? Br J Ophthalmol 2020;104:588-92.

5 Herzlinger RE. Why innovation in health care is so hard. Harv Bus Rev 2006. Available https://hbr.org/2006/05/why-innovation-in-health-care-is-so-hard

6 Hjelm NM. Benefits and drawbacks of telemedicine. J Telemed Telecare 2005;11:60-70.

7 Topol E. The creative destruction of medicine: how the digital revolution will create better health care. Basic Books, 2012. Available https://pdfs.semanticscholar.org/ 69d1/b5579194455f5320a37587b4af6decfe5cf8.pdf.

8 Important coronavirus updates for ophthalmologists. American Academy of Ophthalmology. 2020. Available https://www.aao.org/headline/alert-importantcoronavirus-context (accessed 17 Apr 2020)

9 The Royal College of Ophthalmologists. COVID-19 clinical guidance for ophthalmologists. The Royal College of Ophthalmologists, 2020. Available https://rcophth.ac.uk/2020/04/ COVID-19-update-and-resources-for-ophthalmologists/ (accessed 17 Apr 2020)

10 Sim D, Thomas P, Canning C. Tackling COVID-19 with telemedicine. Ophthalmologist 2020. Available https://theophthalmologist.com/subspecialties/tackling-covid-19-withtelemedicine

11 The Royal College of Ophthalmologists. Increasing demand on hospital eye services risks patients losing vision. The Royal College of Ophthalmologists. 2016. Available https://www.rcophth.ac.uk/2016/03/increasing-demand-on-hospitaleye-services-risks -patients-losing-vision/ (accessed 30 Mar 2020)

12 My eye care and coronavirus. Moorfields Eye Hospital NHS Foundation Trust. Available https://www.moorfields.nhs.uk/my-eye-care-and-coronavirus (accessed 17 Apr 2020)

13 Gunasekera CST6 ophthalmology Norfolk and NE. Near telemedicine during COVID-19 using iPads and iPhones to minimise face-to-face contact. Available https://www. rcophth.ac.uk/wp-content/uploads/2020/03/Norfolk-and-Norwich-Near-iPadTelemedicine-during-Covid.pdf

14 Rapid response. Bluestream Health. Available https://www.bluestreamhealth.com/ rapid-response/ (accessed 18 Apr 2020)

15 Jones A. Pandemic diaries. The Ophthalmologist. 2020. Available https://theophthal mologist.com/subspecialties/pandemic-diaries (accessed 17 Apr 2020)

16 Kortuem K, Fasler K, Charnley A, et al. Implementation of medical retina virtual clinics in a tertiary eye care referral centre. Br J Ophthalmol 2018;102:1391-5.
17 Kern C, Kortuem K, Hamilton R, et al. Clinical outcomes of a hospital-based teleophthalmology service: what happens to patients in a virtual clinic? Ophthalmol Retina 2019;3:422-8

18 Sim DA, Mitry D, Alexander P, et al. The evolution of teleophthalmology programs in the United Kingdom: beyond diabetic retinopathy screening. J Diabetes Sci Technol 2016;10:308-17.

19 De Fauw J, Ledsam JR, Romera-Paredes B, et al. Clinically applicable deep learning for diagnosis and referral in retinal disease. Nat Med 2018;24:1342-50.

20 Anderson S, Broadbent DM, Swain JYS, et al. Ambulatory photographic screening for diabetic retinopathy in nursing homes. Eye 2003;17:711-6.

21 Faes L, Bodmer NS, Bachmann LM, et al. Diagnostic accuracy of the Amsler grid and the preferential hyperacuity perimetry in the screening of patients with age-related macular degeneration: systematic review and meta-analysis. Eye 2014;28:788-96.

22 Liu X, Faes L, Kale AU, et al. A comparison of deep learning performance against health-care professionals in detecting diseases from medical imaging: a systematic review and meta-analysis. Lancet Digit Health 2019. Available https://www.science direct.com/science/article/pii/S2589750019301232

23 Kong T, Scott MM, Li Y, et al. Physician attitudes towards-and adoption of-mobile health. Digit Health 2020;6:2055207620907187.

24 Pifer R. Patient use of digital health tools lags behind hype, poll finds. Healthcare Dive 2019. Available https://www.healthcaredive.com/news/patientuse-of-digital-health-tools-lags-behind-hype-poll-finds/562778/ (accessed 17 Apr 2020)

25 Office for Civil Rights (OCR). Notification of enforcement discretion for telehealth. HHS gov. 2020. Available https://www.hhs.gov/hipaa/for-professionals/special-topics lemergency-preparedness/notification-enforcement-discretion-telehealth/index.html (accessed 18 Apr 2020)

26 Alder S. HIPAA Guidelines on Telemedicine. HIPAA J. Available https://www.hipaa journal.com/hipaa-guidelines-on-telemedicine/ (accessed 18 Apr 2020)

27 Li B, Powell A-M, Hooper PL, et al. Prospective evaluation of teleophthalmology in screening and recurrence monitoring of neovascular age-related macular degeneration: a randomized clinical trial. JAMA Ophthalmol 2015;133:276-82

28 Schwartz R, Loewenstein A. Early detection of age related macular degeneration: current status. Int J Retina Vitreous 2015;1:20.

29 Wang Y-Z, He Y-G, Mitzel G, et al. Handheld shape discrimination hyperacuity test on a mobile device for remote monitoring of visual function in maculopathy. Invest Ophthalmol Vis Sci 2013;54:5497-505.

30 Schmid MK, Thiel MA, Lienhard K, et al. Reliability and diagnostic performance of a novel mobile app for hyperacuity self-monitoring in patients with age-related macular degeneration. Eye 2019:33:1584-9.

31 Berg BL. Qualitative research methods for the social sciences. 2001. Available http:// repository.umpwr.ac.id:8080/bitstream/handle/123456789/3723/qualitative research_methods_for_the_social_sciences.pdf? sequence $=1$

32 The The American Society of Retina Specialists. Global trends in retina - the American Society of Retina Specialists. Available https://www.asrs.org/sections/international/ global-trends-in-retina ( )

33 Bradburn NM, Rips LJ, Shevell SK. Answering autobiographical questions: the impact of memory and inference on surveys. Science 1987;236:157-61.

34 Mehrotra A, Chernew M, Linetsky D, Hatch $\mathrm{H}$ and Cutler D. The rebound in visits has occurred across all specialties. Available https://www.commonwealthfund.org/chart/ 2020/decline-visits-was-generally-larger-among-surgical-and-procedural-specialtiesand (accessed 28 Apr and 23 Sept 2020) 